\title{
Effects of Informal Saving Schemes Accumulative Deposits on Livelihoods in Laikipia County, Kenya
}

\author{
Wambugu Maranga Muriu ${ }^{1}$, Dr Karuri Thiongo ${ }^{2}$ \\ ${ }^{1}$ Post Graduate scholar, ${ }^{2}$ School of Social Sciences \\ Mount Kenya University, P.O. Box 342-0100, Thika, Kenya
}

\begin{abstract}
Informal saving schemes is a way in which people pool their savings together and provide loans to facilitate income generating ventures of all inclusive economic activities. The study object was to assess the effects of accumulative deposits made at Informal saving groups contribution on household livelihoods improvement. The research was carried out in Laikipia County due to targeting Informal saving schemes in arid and semi-arid areas. Adverse selection theory of financial markets and sustainable livelihood approach theory guided the study. Simple random sampling and probabilistic used to select sample size of 90 respondents comprising of 78 members, 7 officials, 3 managers and 2 opinion leaders. Primary data collected on guided predetermined household ten core activities where questionnaires and interview used as data collection instruments, accumulative deposits are instrumental in ascertainment of loan sizing and a valued discipline in sustainability, descriptive and deductive statistics like tables used, where members have claimed success with improved family circle income with accumulative deposits which is fundamental to sustain human basic needs and social change motivator. Commend the amendment of existing policies and charters, to protect the Informal savings groups from Ponzi schemes, and appointment of an aggregator for technical support to Informal saving schemes.
\end{abstract}

Keywords: Informal saving groups, Accumulative deposits, Livelihood improvement, Sustainability, Economic activities.

\section{INTRODUCTION}

Informal saving schemes are ways used for mobilizing savings as well as propelling credit facilities to income generating activities in country areas and SMEs in sub-urban settings. One in every 10 people globally subsists on less than US\$ 1.90 per day, according to (World Bank, 2016) estimates as majorities live in rural areas and engage primarily in low-productivity, highrisk subsistence farming and related activities (Olinto, 2013). Regardless of dismissal from our opinion of traditional banking, a growing number of people are taking a premium in Informal saving schemes which they consider more convenient and open than the formal money related organizations as they are quicker in complimenting financial services to small earners having the goal of improving household incomes.

The most widely recognized models like accumulated saving and credit association (ASCAs). ASCAs operate by group members making contribution, as opposed to rotation payment; the group money for ASCAs is given as loans which in turn will attract small interest when paying back. These contributions loaned to members or those trusted non-members. After a specific timeframe probably six to twelve months, money contributed and interest returns from loan advanced are repaid to contributors (Goss, 2011).

(World Bank, 2018), saw that under half about family units in underdeveloped nations had the option to get budgetary administrations given by formal organizations, contrasted with more than $70 \%$ in created wealth. Universally, of the 193.6 million families which are ordered as impoverished around the world, $47.8 \%$ were found to be in the scope of arriving at the formal budgetary organization's administrations. As proof, (Leiken, 2010) opined 3,652 microfinance's were assessed to have more than 205 million customers by December 31, 2010. Among them, more than 137 million were discovered to be beneath the neediness line after securing an advance just because where 82.3 percent were ladies. Close to microcredit administration accessed by low class nations, it is also found in the ground- breaking states like USA, it was assessed that 37 million speaking to $12.6 \%$ will in general work underneath the destitution line (United Nations (UN), 2005). 
In Kenya, as indicated by (Kenya Vision 2030) that was propelled in 2008, Action Aid International Kenya presented Informal saving schemes in Eastern Kenya by a project that planned for assisting identified household income for persons that were from the most part which are affected by climate change, cattle rustling and different disasters (Kenya, Ministry of Planning and National Development, VISION 2030, 2016). Even with the massive recruitment and benefits accrued from Informal saving schemes there is considerable number of member defaulters this necessitating a research to examine the cause a study to and come up with policy recommendations.

The lengthy process of loan application, elaborate terms and conditions not clearly disclosed hence making the disadvantaged people avoid the formal financial sector (Nguyet, 2014) (Republic of Kenya, FinAccess Household Survey , 2016). The formal saving schemes alternative is gaining popularity amongst the disadvantaged populace regardless of the efforts of the government encouraging formal financial sector borrowing. In reference to (Republic of Kenya, 2016, FinAccess Household Survey, 2016) outcome were formal sectors $(8.1 \%)$, whereas alternative sector $(8.7 \%)$ escalated a mountable significance with consumers of their products. Informal saving schemes mobilize more funds than formal financial services to finance SMEs in Kenya. Laikipia County has a human poverty index (HPI) of $57.3 \%$ compared to national poverty index $29.1 \%$, the index includes four aspects of human attributes: life expectancy, levels of consciousness acquisition, productivity standing and social cohesion. The index also estimates poverty along three spheres of human progression; protracted and robust existence, and life of dignity. Again HPI is postulated on comprehension that human progression is about magnifying chances, then deprivation means lack of fundamental chances and alternatives. Hence, the study was executed in Laikipia County to assess the effects of Informal saving groups accumulative deposits on poverty alleviation and reduction of compounded human poverty index comparatively (KNBS, 2017). It is not clear of the effects of Informal saving schemes contributions to improvement of household income of rural folks and its significance. The study therefore, as object aimed to assess the effects of accumulative deposits made at Informal saving groups contribution to household's livelihoods improvement and subsequent research question of how? This study also attempts to identify drivers and circumstances that enhance wider adoption (embracing) of the sector. The finding is crucial to the policy makers, researchers and investors in these informal saving groups to review and enact policies geared towards technical and financial feasibility support for achievement of development and economic growth nationally.

The research outcome, supported by management analysed interview response, the average loans obtained by members is Kshs 20,000 and above, this has been achieved by accumulative deposits done monthly and weekly for those in daily business ventures. Whereas $90 \%$ of the participants were members who venture in agri-business, small livestock keeping and daily farming. Other $10 \%$ of the participants were on SMEs, mainly selling of goods and services. Assessment on the ten core activities; clothing, housing, water, education, food, medical, social capital, finance, business and assets. Study outcome shows that on average $83.5 \%$ of the participants response rate returned indicated improvement on livelihoods from loans obtained on accumulated deposits on the ten core activities. Whereas $16.5 \%$ of the participant's response indicated they experienced a minimum improvement due to prioritization of core activities as per individual needs. This was prompted by social dynamics, for example, age factor, composition of household and responsibilities greatly affected decision-making on prioritization of needs and wants, which determines the accumulative deposits and expenditure on accrued benefits.

From the research survey administered questionnaire analysis on the ten core activities, prioritization was activities on basic human needs and their facilitators' activities; clothing, housing, food, water, finance and social capital. While education activity was viewed as long term impact to reduce poverty, also took significant consideration on the expenditure listing, but other core activities i.e. medical, business and assets were optional and not pressing like human basic needs, viewing them as emergency cushions or venture on surplus income. The outcome observed that Informal saving schemes may guarantee individual financial needs. Also the study affirmed that members from the Informal saving groups have claimed success with improved household income.

\section{LITERATURE REVIEW}

In developing countries, Informal saving schemes within financial sector co-exists with the formal financial sector and increasingly being embraced than the formal sector (Bett, 2013). The popularity of Informal saving schemes arise because individuals view them as a self-regulating tool that assists them to save in order to improve their household livelihood to scale up income generating activities and purchase an indivisible good.

Adverse selection happens when there is asymmetric (unequal) information between buyers and sellers. The unequal information distorts the market and leads to market failure (Hayers, 2019). Recently, even with the consistently developing of the financial sector (Wang, 2014), formal funds offered more help for non-state division and the result is yet encouraging. Further, government and controllers revealed the centre and little real capital and advanced Enterprises Market in Ghana, since the vetting instrument 
appeared exceptionally severe, at hand was a lot of centre and private company which got no opportunity to get to financing. As such they moved to seek assistance from Informal saving schemes to access credit facilities (Decardi-Nelson, 2012).

Loan cost control and credit apportioning which have been remembered for budgetary prevention unscrupulous began the additional capital flexibly and request out of formal account that is the reason Informal sparing plans existed.

Loan fee controlling had two reactions of establishment of organization, rise and improvement of Informal sparing plan. Because of gracefully side, interest rate controlling created incredibly low enthusiasm of store, and the loan fee had been bent. The loan fee didn't reflect genuine inclination of contributor, in that capacity, investors want to increase high pay of store from the Informal sparing plan. That was eluded "money related disintermediation". Its procedure gave the capital asset to the Informal sparing plan. Because of interest side, financing cost controlling makes the business bank credits rate do not mirror exact genuine market rate denoting spoke to the degree of starting of venture capital. Not to mention the negligible efficiency of capital (Piketty, 2019).

Informal a number of saving schemes of some sort are known to work in about portion of every single African nation (Lingson, 2019). Basic to these Informal sparing plans is they will in general be socially homogeneous. These Informal saving groups conceivably help to manufacture what (Kwena, 2013) called 'social security' by expanding data streams giving advantages (Which could be cut off) to individuals, and filling in as cardinal purpose of social collaboration. Casual sparing gatherings, henceforth, notwithstanding its immediate job in assembling reserve funds, may serve to relieve the data and authorization challenges related with other budgetary exchanges. (Care, 2013), presupposes that rigorous demand by distinct financial sector leads to inefficacious reserve of credit facilities in sub-urban areas. He observed that these requirements led to financial repression as advocated and explained the widespread use of Informal saving schemes arrangements in developing countries. In relation to this study, individuals resulted to Informal saving schemes as a result of unfavourable identification and ethical vulnerability tendencies that are exhibited by formal financial institutions. The charge of obtaining loan in banks and micro-finances is high terms of interest rate, processing fee, insurance charge, processing period and tome spent in the banks. Hence, the convenience of Informal saving schemes and negotiability makes them popular among the disadvantaged in both rural and urban centres.

Conforming to (Morse, 2013), acknowledgement of structures that configures the basis of sustainable approach. Where one, defines the procedure which accords the government and development partners to complimentary initiate development programs to assist the needy as intentional interventions. These programs are assumed with the inclusive involvement of the beneficiaries as the accrued benefits or gains will be sustained beyond the donors exit. Further impact on the ideal of feasible employment and in reality maintainable business approach theories is the field of new family unit financial aspects which developed during the 1980s and its emphasis on family work, pay age and use, regardless of whether there were perceived restrictions to seeing families in such mechanical terms.

According to (Simon, 2010) and (Wlokas, 2011, April) discourses 'Sustainable Urban Livelihoods Approach, on similarity, and as such, Sustainable Livelihood Approach is based on this information flow and occurrences contrary to other directions. The application of structures and devices to give a firm base to intercession is positively not one of kind to sustainable livelihood approach. The writing on manners by which intercessions all things considered, explicitly strategy can be founded more on proof is significant and gone back for a long time. As of late, there has been the ascent of 'hypothesis of progress' as intends to animate how a venture's exercises brings out change (Funnell, 2011). This would incorporate changes of the size of family unit through foundations and without a doubt of the state. The organizations tends to include changes of institutional approach, whereas in the event that strategy did not depend on proof, at that point the odds may not have the ideal impact and even have unintended, maybe undesirable results.

It was pointed out that Sustainable Livelihoods Approach theory is established upon the thought that mediation must be founded on energy about what supports vocations and conceived from what can be called a deliberate way to deal with improvement distinguished two essential structures. Study by, (Morse and McNamara, 2013), distinguished two essential types of improvement on which the practical business approach is based. Intrinsic turn of events (or what individuals are doing in any case) signifying a wide procedure of progression in human social order derived and facilitated by global integration on digital platform. Intentional development where development projects and programs implemented on poverty reduction adopt an exit strategy on supposition that the additions accomplished would proceed after the withdrawal of donor funding. Therefore, it is a critical theory to a renowned path that will enhance the performance of Informal saving schemes to improve the household livelihood.

Conforming to (Mungiru, 2015), examined the impacts in respect to Informal saving schemes with presentation of MSEs in Kiambu County, Kenya. The discoveries of the examination communicated of numerous respondents supported credit from Informal sparing gatherings, associates and family, and exchange endeavours in light of the fact these sources emphatically impacted their business execution. All things being equal, results demonstrated that shylocks account affected the presentation of 
MSEs. In their investigation, the specialists utilized just the quantitative way to deal with gather information through survey. This investigation will receive two-prong approach (poll and meeting plans) to accumulate adequate data from the respondents.

Some empirical literature report that Informal saving schemes are across the board in any event, when individuals have sensible access to formal credit markets (Awan, 2015). Loyalty gadget an all the more common clarification for joining an Informal sparing plan is that individuals may choose to subscribe to a provided sparing plan so as to forestall an expected abuse of cash. (Basole, 2011),states that Informal sparing plans individuals may have time conflicting inclinations, and show that, under hyperbolic limiting Informal sparing plans are manageable without social weight and disciplines. This suggests, when people are basic exponential discounters with no dedication issues, the motivating force to shape Informal sparing gathering could be somewhat constrained or non-existent without authorizing systems (Anderson, 2010). By the way, this doesn't imply that we can without much of a stretch recognize benevolence and basic personal responsibility in Informal sparing gatherings members. Besides, such clarification doesn't fit the exact perception that Informal sparing plan individuals are frequently hesitant to utilize discipline techniques to uphold reliable conduct, as contented by (Kesnata, 2015).

Assembling reserve fund is never simple for poor people. The issue is exasperated in light of the fact that they don't have any bartering capacity to acquire formal money related administrations. They ordinarily can't talk about their credits value and sparing issues with the formal budgetary foundations. According to, (Kenya, F.S.D. FinAccess National Survey , 2013) , places it in a solidarity expression. "The individuals who hold power don't comprehend the interest and the individuals who comprehend the interest don't hold power". (Manu, 2016), investigated the impact of Informal sparing plans on the exhibition of SMEs in Kumasi, Ghana and found out that the majority $(56.8 \%)$ of the respondents obtained their start-up finance from their potential savings, $27.4 \%$ got starting capital from the associates and kin, $8.4 \%$ accessed it from microfinance and $7.4 \%$ acquired it from formal financial institutions. Manu concluded that the Informal saving schemes contributed to improved household livelihood's in Ghana.

(Koech, 2012), researched on a study, the effects of Informal saving schemes in accumulating funds for micro-enterprises in Kenya with sample size of 73 respondents from a target population of 729 small micro-enterprises in Kericho County. The study results indicate that Informal saving groups were the most common source of Informal credit for SMEs accounting for 35.4\% of the total respondents, followed by kin and associates who accounted for $32.3 \%$ and suppliers and mobile financial institutions at $10.8 \%$. This research did not look at a specific Informal saving scheme to relate it to the source of the loan. Additionally, (Obiria, 2020) emphasized that Informal saving schemes had improved household livelihood and rendered them substantially financial independent on meeting the basic needs, education and health insurances.

(Amunga, 2013), affirms that fundamental objective of Informal saving schemes (table banking and chamas) are availing financial services nearer to the disadvantaged for purposes of empowering them for improvement of household income. Further, Informal saving scheme is unique as it is a recipe of Informal saving groups based on common interest as the social structure provides, creates benefits realized on group security as well as family loan securities (Morse \& McNamara, 2013).

(Ruto, 2015), states that Informal saving schemes inter-alia table banking and chamas in a monetary model that empowers individuals from Informal sparing gatherings to contribute, obtain just as set aside cash for enterprising exercises, which is handily profited to individuals as present moment or long haul credit. (Glanz, Rimer \& Lewis, 2012), affirms that members from the Informal saving groups have claimed success with improved household income. Saving in Informal saving groups/schemes is accumulatively done daily/weekly/monthly with as small as one hundred shillings per day, with this small saving enabling one to qualify for small loans. Hence, the study was in its findings assessed the effects of accumulative deposits at Informal saving groups contribution to household livelihoods improvement as ultimate achievement, as it is key in determination of loan size and a valued discipline in sustainability of Informal saving schemes.

However, there is inadequate proof in studies on the effects of Informal saving schemes with improving rural household livelihoods (Brannen, 2010), People in the rural areas are most active participants on the performance of Informal savings, hence, the need to examine their involvement in savings and how it impacts to their livelihoods especially on the rural economy. Therefore, the input of the schemes to the improvement of socio-economic status of the disadvantaged is a subject that requires scientific investigation (Odokonyero, 2012). Where this research, aims to address the mastery aperture with its findings. Hence, theoretical and empirical review asserts that Informal saving schemes can have a significant glare on household income, economic and development growth. 


\section{METHODOLOGY}

A research design lays down procedure in which the researcher intends to carry out the developed research problem (MOUTON, 2015), highlights the instructions and guidelines of procedures in dealing with the study question. As such this study used exploratory research that involved both cross-sectional survey and quantitative methods. Conforming to (Kohlman, 2013), crosssectional inquiry is an observational examination that investigates data collected from a representative portion at a specific point in time, quantitative is the systematic empirical study of observable fact through statistical techniques, therefore, in this study Informal saving groups with accumulative deposit saving and their amount saved in Informal saving schemes was investigated.. The research applied a mixed research method whereby the researcher combined both elements of qualitative and quantitative research approaches (e.g. use of qualitative and quantitative view points, data collection, analysis, inferences techniques) for the broad purpose of breadth and depth of understanding and corroboration.

Target population and sample size; the study population constituted total target population of 920, with 90 respondents selected using simple random sampling, expressed on categories as, scheme members 800(78 respondents), officials 70 (7 respondents), managers 30(3 respondents), opinion leaders 20(2 respondents). Data collection method and instruments; in this study, data gathering used, questionnaire, interview, focus group and key informants practices. The application of the instruments purposes was maintained such that the focus of the research intent purpose of the study was explored to the furtherance of the research objective. The researcher ensured that the instruments were developed with the conformity of the research objects of the study. A pilot study was conducted by the researcher to examine the validity and reliability of research instruments.

\section{FINDINGS}

A sample study of 90 respondents was issued with questionnaires, where 80 questionnaires were received back duly filled, this amounting to return rate of $88.9 \%$. As stated by (Bernard, 2006), for call back questionnaire a return rate of at the minimum of $70 \%$ is admissible. This sub division confers the effects of accumulative deposits made at the Informal saving schemes at household level on ten core activities (clothing, housing, water, education, food, medical, social capital, finance, business and assets).

Table 1: Accumulative Deposits Impact on Core Activities

\begin{tabular}{|l|l|l|l|}
\hline $\begin{array}{l}\text { Core } \\
\text { Activity }\end{array}$ & Response & Frequency & Percent \\
\hline Clothing & Yes & 76 & $95 \%$ \\
\hline & No & 4 & $5 \%$ \\
\hline & & $\mathbf{8 0}$ & 100 \\
\hline Housing & Yes & 73 & $91 \%$ \\
\hline & No & 7 & $9 \%$ \\
\hline & & $\mathbf{8 0}$ & $\mathbf{1 0 0}$ \\
\hline Water & Yes & 57 & $71 \%$ \\
\hline & No & 23 & $29 \%$ \\
\hline & & $\mathbf{8 0}$ & $\mathbf{1 0 0}$ \\
\hline Education & Yes & 70 & $87.50 \%$ \\
\hline & No & 10 & $12.50 \%$ \\
\hline & & $\mathbf{8 0}$ & $\mathbf{1 0 0}$ \\
\hline Food & Yes & 77 & $96 \%$ \\
\hline & No & 3 & $4 \%$ \\
\hline & & $\mathbf{8 0}$ & $\mathbf{1 0 0}$ \\
\hline Social & Yes & 66 & $82.50 \%$ \\
\hline Medical & No & 14 & $17.50 \%$ \\
\hline & & $\mathbf{8 0}$ & $\mathbf{1 0 0}$ \\
\hline & & 70 & $87.50 \%$ \\
\hline & & $12.50 \%$ \\
\hline
\end{tabular}




\begin{tabular}{|l|l|l|l|}
\hline & & $\mathbf{8 0}$ & $\mathbf{1 0 0}$ \\
\hline Finance & Yes & 69 & $86 \%$ \\
\hline & No & 11 & $14 \%$ \\
\hline & & $\mathbf{8 0}$ & $\mathbf{1 0 0}$ \\
\hline Business & Yes & 61 & $76 \%$ \\
\hline & No & 19 & $24 \%$ \\
\hline & & $\mathbf{8 0}$ & $\mathbf{1 0 0}$ \\
\hline Assets & Yes & 50 & $62.50 \%$ \\
\hline & No & 30 & $37.50 \%$ \\
\hline & & $\mathbf{8 0}$ & $\mathbf{1 0 0}$ \\
\hline
\end{tabular}

Clothing: Considering clothing is human basic need. As exhibited on Table 1; the research outcome indicates 95\% of the participants said clothing has been improved by the accumulative deposits increasing the amount of loan that can be sought from the Informal saving scheme. While 5\% of the participants returned it did not affect their clothing, further analysis cited the age factor young category due to social dynamics limitation of core activities.

Housing: Considering housing is a basic human need. As exhibited on Table 1; the research outcome indicates that $91 \%$ of the participants said that accumulative deposits have affected the housing activities but in a positive manner as they were able to change their housing infrastructure and compounds. Whereas $9 \%$ who were either living with parents or rented residence, the question of housing benefits could not arise.

Water: Given that, water is essential to human life. As exhibited on Table 1; the research outcome indicates that accumulative deposits increased individual loan size accessed; therefore, the water access point was achieved to desired status that was $71 \%$ of the respondents. Whereas $29 \%$ of the respondents despite accessing more funds from accumulative deposits, water access activities was not within their priority as they rented houses or stayed with parents.

Education: Considering education is instrumental in transformation of human life both socially and economically. As exhibited on Table 1; the research outcome indicates that accumulative deposits increases loan size thus enabling them to access and afford the standard of education so desired for self and other household members, this was $87.5 \%$. Whereas $12.5 \%$ despite improved loan intake due to accumulative deposits they had no commitment on this core activity.

Food: Considering that food is a basic human need and hence, a prioritized core activity. As exhibited on Table 1; the research outcome indicates that $96 \%$ of the participants said that due to sizeable amount of loan accrued from the accumulative deposits in the Informal saving schemes, they were able to achieve optimal food security basket from improved farming and appropriate technology application. Whereas $4 \%$ said this core activity was not their priority as they lived with parents or pursing other core activities.

Medical: Considering is a determinant in human life. As exhibited on Table 1; the research outcome indicates that $82.5 \%$ of the participants said that the increased accumulative deposits in the Informal saving scheme stood as determinant to increase loan size, therefore, the sustenance of medical insurance cover, social welfare or any emerging minor medical issue was no longer worrying. While $17.5 \%$ of the participants, were either ignorant, insensitive on medical insurance cover and undue caution on emerging medical issues, due age factor and lack of responsibilities held or presumed.

Social capital: Considering interpersonal principles are a receipt of individual satisfaction and capability leading to a societal cohesiveness and sense of belonging, with both wealth and health environment. As exhibited on Table 1; the research outcome indicates that $96 \%$ of the participants had achieved a disciplined culture of saving, resources mobilization, a wider pool of gaining experiences on interaction and proceeds of increased loan amounts obtained from the accumulative deposits. Whereas $4 \%$ of the participants had not distinctively settled on their social lives, therefore, could not fully exploit this core activity.

Finance: Formally the financial capability of a family circle is a rating of their ability and a show of financial footing for the family. As exhibited on Table 1; the research outcome indicates that $86 \%$ of the participants said that the accumulative deposits had enabled them to access the desired loan amounts promptly, as they had traceable discipline of saving. Whereas $14 \%$ of the participants were either so committed on other core activities such that could not sustain a gradual increase in accumulating deposits to ripe benefits. 
Business: In the view of the fact, that income generating activities are core business in sustenance of Informal saving scheme by members, leading to accumulative deposits, loan uptake and repayment. The up scaling of business and diversification of income generating activities was instrumental. As exhibited on Table 1; the research outcome indicates that $76 \%$ of the participants were able to maximize on this aspect of accumulative deposits to increase their loan uptake, as they visualized that the more the money, the more flow of ideas and actualization of the same. Whereas $24 \%$ of the participants had their accessed loan directed to other prioritized core activities, therefore, missing on this activity.

Assets: Given that family benefits are viewed as improved socio-economic status. The dissimilarity between high-yielding assets against tangible and intangible assets is contemplated due to its significance on supplementary characteristic of family spheres, The accrued benefits of accumulative deposits at the Informal saving schemes enhances this core activity as it impacts greatly on the household due to achieved loan security. As exhibited on Table 1; the research outcome indicate that $62.5 \%$ of the participants said that accumulative deposits in the Informal saving scheme had increased their loan bargaining and purchase power, therefore, able to budget for their desired acquisition of assets. While $37.5 \%$ of the participants priority was on other core activities, hence, no impact on this activity.

\section{CONCLUSION}

Accumulative deposits made at the Informal saving groups are the determinants of loan sizing. From the research outcome participants in Informal saving groups embraced the need to pool resources together for access, affordability and sustenance of financial source. Assembling reserve fund is never simple for poor people. The issue is exasperated in light of the fact that they don't have any bartering capacity to acquire formal money related administrations. They ordinarily can't talk about their credits value and sparing issues with the formal budgetary foundations. Hence, the research concludes that accumulative deposits made at Informal saving schemes contribute to livelihoods improvements as ultimate achievement as it is instrumental in ascertainment of loan sizing and a valued discipline in sustainability of Informal saving schemes.

The research further commends, that to preserve the gains of Informal saving schemes members accumulative deposits, a need arises to amend the existing policies and charters to protect them from Ponzi schemes and shylocks, enticing them to withdraw deposits for suspicious financial gains, this can be done with the control of an aggregator to recognize the Informal saving schemes to benefit from the women/youth fund enterprises without subjecting them to undue appraisal by the formal financial intermediaries due to vested interest on commercial aspect. The tax-free financial transactions enjoyed by Informal saving schemes, due to their informal setting directly leads to increase, GDP per capital and poverty reduction strategy.

A need for further research in urban and sub-urban areas, where social dynamics, cultural and religious foundations are enshrined to test the inference on their geographical settings, in application of Informal saving schemes or groups, especially where these foundations dictates the investment plan on income generating activities.

\section{REFERENCES}

Amunga, H. A. (2013). The Four Pillars of table banking, the microcredit approach.

Anderson, S. \&. (2010). The economics of ROSCAs and intra household resource allocation. The Quarterly Journal of Economics

Awan, A. G. (2015). Role of microfinance in poverty alleviation: Evidence from Pakistan. American Journal of Trade and Policy, , 2(1), 37-44.

Basole, A. \&. (2011). Relations of production and modes of surplus extraction in India: Part 1-agriculture. Economic and Political Weekly, 41-58.

Bernard, H. R. (2006). Methods in Anthropology. Qualitative and Quantitative , 424.

Bett, J. (2013). Discussion Paper No. 152 of 2013 on Determinants of Informal Finance Use in Kenya.

Brannen, C. F. (2010). An impact study of the village Savings and Loan Association (VSLA) program in Zanzibar, Tanzania.

Care, D. (2013). Economic costs of diabetes in the US in 2012. 
Decardi-Nelson, I. A.-A. (2012). The Informal sector and mortgage financing in Ghana. Ghana Journal of Development Studies, , 9(2), 136-152.

Funnell, S. C. (2011). Purposeful program theory: Effective use of theories of change and logic models. John Wiley \& Sons , (Vol. $31)$.

Goss, S. I. (2011). "The next challenge: Channeling savings through mobile" The Mobile Services Development Report. The Bill $\&$ Melinda Gates Foundation.

Hayers, A. (2019). The socio-technological lives of bitcoin. Theory, Culture \& Society, 36(4), 49-72.

Kenya, F.S.D. FinAccess National Survey . (2013). Profiling developments in financial access and usage in Kenya. Nairobi: Central Bank of Kenya.

Kenya, Ministry of Planning and National Development, VISION 2030. (2016). A Globaly Competitive and Prosperous Country. Nairobi:: Popular Version.

Kesnata, J. \&. (2015). "Impact of Women Empowered through Community Savings Groups on the wellbeing of their Families: A Study from Mgubwe, Tanzania". Interdisciplinary Journal of Best Practices in Global Development, , Vol. 1, Article 4.

KNBS. (2017). Home-Kenya National Bureau of Statistics. Nairobi, Kenya.

Koech, H. K. (2012). The role of informal credit schemes in mobilizing funds for micro-enterprises in Kenya. (Doctoral dissertation. Kenyatta University).

Kohlman, M. H. (2013). Introduction: Intersectional Dynamics of Gender, Family and Work. In Notions of family intersectional perspectives. Emerald Group Publishing Limited.

Kwena, R. M. (2013). Extending pension and saving scheme coverage to the Informal sector: Kenya's Mbao Pension Plan. International Social Security Review, , 66(2), 79-99.

Leiken. (2010). Microfinance. A tool for poverty reduction. Seniors Honors Project, Paper 300.

Lingson, L. (2019). The role of Informal financial institutions in improving social wellbeing of their members in Geita District, Tanzania. (Doctorial dissertation, Sokoine University of Agriculture) .

Manu, H. B. (2016). The effects of savings and loans companies on the operations of small and medium enterprises (SMEs) in Kumasi Metropolis (Doctoral dissertation).

Morse, S. \&. (2013). Sustainability and Sustainable Livelihoods: In Sustainable Livelihood approach. Springer, Dordrecht .

MOUTON, J. (2015). Understanding Social Research. Pretoria: JL, Van Schaik.

Mungiru, J. W. (2015). Effects of informal finance on the performance of small and medium enterprises in Kiambu County. International Journal of Scientific and Research Publications, , 5(11), 338-362.

Nguyet, K. C. (2014). Why do Small and Medium Enterprises Need to Access Informal Credit? The Case of Vietnam. International Finance and Banking.

Obiria, L. O. (2020). Influencing of Financing on Performance of Small and Medium Women Owned Enterprises in Kwale County, Kenya. International Journal of Current Aspects in Finance, Banking and Accounting, , 2(2), 35-45.

Odokonyero, K. (2012). ORGANIC FARMING AND SOCIAL CAPITAL APPROACH IN THE RESTORATION OF SUSTAINABLE AGRICULTURE LIVELIHOODS IN A POST-CONFLICT SETTING: A CASE OF NORTHREN UGANDA.

Olinto, P. B. (2013). The state of the poor., Where are the poor, Where is extreme poverty harder to end, and what is the current profile of the world's poor. Economic premise, , 125(2), 1-8.

Piketty, T. Y. (2019). Capital accumulation, private property, and rising inequality in Ghana, 1978-2015. American Economic Review, , 107(7), 2469-2496. 
Republic of Kenya, FinAccess Household Survey . (2016). Financial Sector Deepening. Nairobi: FSD Printer.

Ruto, T. (2015). Women groups; From Welfare to Small-Scale Business in Kenya. In Small Enterprises Development.

Simon, D. \&. (2010). Urbanizing the global environmental change and human security agendas. Climate and Development, , 2(3), 263-275.

Wang, Q. D. (2014). Deepening reform of the financial system and improving the financial market system-learning the third plenary session of 18th cpc central committee. Journal of the party school of shengli Oilfield.

Wlokas, H. L. (2011, April). What can solar water heating contribute to the livelihoods of low-income households. In Domestic Use of Energy Conference.

World Bank. (2016). Poverty and shared prosperity 2016. talking on inequality.

World Bank. (2018). World devlopment report 2019:. The changing nature of work. 